\title{
Infective endocarditis with brain lesions misdiagnosed as viral encephalitis
}

\author{
Jing-Jing Zhang, Guo-Dong Feng \\ Department of Neurology, Xijing Hospital, the Fourth Military Medical University, Xi'an 710032, Shaanxi, China.
}

\section{A B S T R A C T}

Infective endocarditis (IE) is caused by infection of the endocardial surface of heart. It typically affects one or more heart valves, the mural endocardium, or a septal defect. In recent years, many IE patients suffered from atypical initial symptoms. Here, in this case report, a 12-year-old patient was initially diagnosed as encephalitis. However, it was later noticed that this was a misdiagnosis for the following reasons: the echocardiography showed a vegetation attached to his mitral valves; the cranial magnetic resonance imaging showed lesions that were consistent with a cardioembolic distribution. The final diagnosis was IE.

Key words: Antiplatelet agents, embolic events, infective endocarditis

\section{INTRODUCTION}

Infective endocarditis (IE) is caused by infection of endocardial surface of heart. It may affect one or more heart valves, the mural endocardium or a septal defect. $^{[1]}$ Embolic events are serious complications, and it is estimated that they occur in $10 \%$ to $50 \%$ in IE patients. ${ }^{[2]}$ Embolic stroke is among the most notable and life-threatening ones. It interferes with patient normal activities and can cause death. ${ }^{[3]}$ However, as IE clinical symptoms have become atypical and the morphology and location of embolic intracranial lesions are in diverse forms, it may easily lead to misdiagnosis. ${ }^{[4]}$ Here, we describe a case of cerebral embolism with atypical IE symptoms.

\section{CASE REPORT}

The patient is a 12-year-old male without any previous disease. On November 28, 2014, he got a fever with the body temperature of $39.5^{\circ} \mathrm{C}$. He no longer had fever after infusion. Three days later, he suddenly suffered

Corresponding Author: Dr. Guo-Dong Feng, Department of Neurology, Xijing Hospital, the Fourth Military Medical University, No. 169 Changle West Road, Xi'an 710032, Shaanxi, China. E-mail: fgd2000@163.com

\begin{tabular}{|l|l|}
\hline \multicolumn{2}{|c|}{ Access this article online } \\
\hline Quick Response Code: & Website: \\
\hline & www.nnjournal.net \\
\hline
\end{tabular}

from headache, along with nausea and vomiting. Subsequently, he had an episode of generalised tonic-clonic seizure. These symptoms lasted several minutes. Then he came to his senses, but with low weak voice and slow responses. His cranial magnetic resonance imaging (MRI) was performed in the referring hospital. This revealed the presence of multiple lesions in bilateral cerebellar hemisphere, the right thalamus and occipital lobe. Cerebrospinal fluid was acellular with normal protein and glucose. $\mathrm{He}$ was diagnosed with viral encephalitis and treated with intravenous acyclovir and mannitol. On December 4, the patient suddenly developed a left limbs weakness. At that stage he was then transferred to our clinic.

In the physical examination, we observed that he was having a heart murmur, slow response, low weak voice, slow light reflex in left pupil and left hemiplegia. There were no meningeal signs. Routine blood examination showed mild anemia (hemoglobin $122 \mathrm{~g} / \mathrm{L}$, normal 130-175 g/L). Upon his admission, the following laboratory tests gave a negative result: blood biochemistry analysis, coagulation profile, myocardial

This is an open access article distributed under the terms of the Creative Commons Attribution-NonCommercial-ShareAlike 3.0 License, which allows others to remix, tweak, and build upon the work non-commercially, as long as the author is credited and the new creations are licensed under the identical terms.

For reprints contact: service@oaepublish.com

Cite this article as: Zhang JJ, Feng GD. Infective endocarditis with brain lesions misdiagnosed as viral encephalitis. Neuroimmunol

Neuroinflammation 2016;3:48-50.

Received: 09-07-2015; Accepted: 01-10-2015 
enzymes, thyroid function, erythrocyte sedimentation rate, anti-streptolysin $O$ test, rheumatoid factor, highsensitivity C-reactive protein, blood cultures, and autoantibody series (such as antinuclear antibodies, ds-DNA and so on). The test results of pathogens (bacteria, viruses and treponema pallidum) were also negative in blood. Routine electroencephalogram showed there was no spike or slow waves. Another test on cerebrospinal fluid (CSF) showed no obvious abnormalities. His magnetic resonance angiography revealed that intracranial arteries were normal. His previous MRI showed that all lesions were distributed in the posterior circulation. After reading his MRI report, the consensus was to perform diffusion weighted imaging (DWI). We found hyper-intensity within the areas of lesions [Figure 1]. Carotid artery ultrasound revealed no abnormalities. Transthoracic echocardiography confirmed there was a vegetation (10 $\mathrm{mm} \times 4 \mathrm{~mm})$ attached to mitral valves [Figure 2]. These imaging tests were consistent with IE and cerebral embolism (caused by IE). ${ }^{[5]}$ The patient refused a heart operation, so he was treated with 1.6 million units of penicillin $\mathrm{G}$ sodium for 4 weeks. After 6 months of follow-up, the patient significantly improved and was back to normal life. His re-examination of transthoracic echocardiography showed there was no
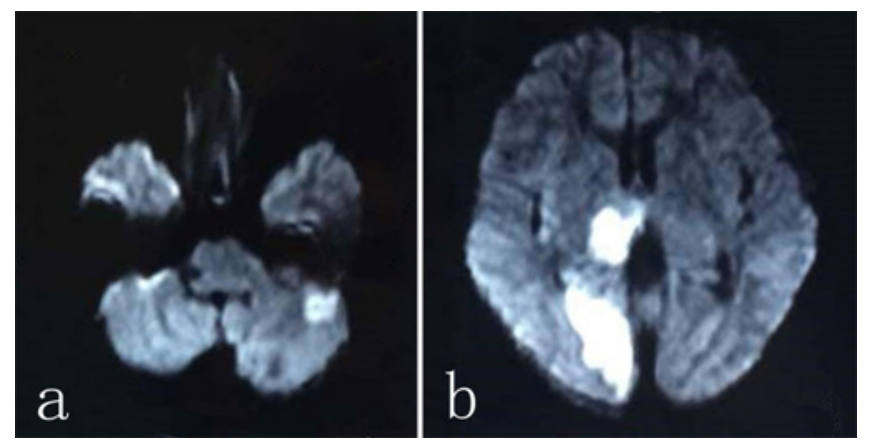

Figure 1: Diffusion weighted imaging and found enhancement within multiple lesions in (a) bilateral cerebellar hemisphere; (b) the right thalamus and occipital lobe

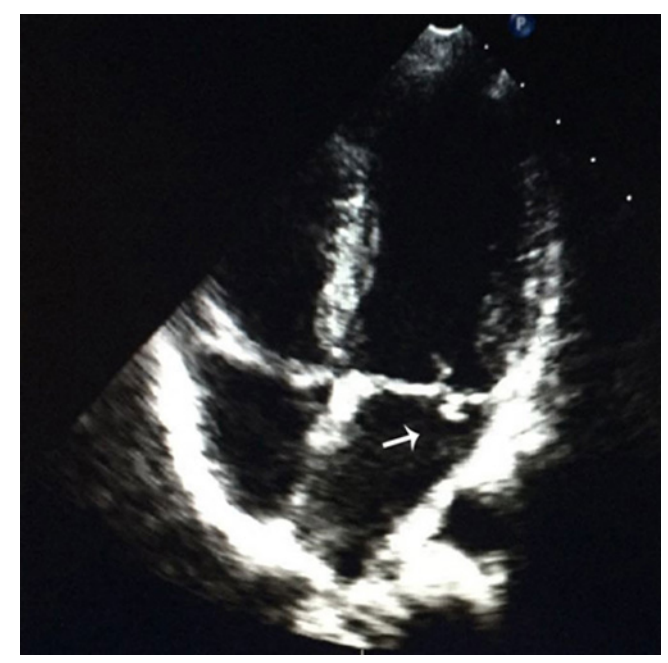

Figure 2: Transthoracic echocardiography showed there was a vegetation $(10 \mathrm{~mm} \times 4 \mathrm{~mm})$ attached to mitral valves mitral valves vegetation.

\section{DISCUSSION}

Clinical manifestations of IE have a variety of symptoms and signs. These include fever, arterial embolic phenomena (cerebral embolism, renal embolism, pulmonary embolism, etc.), heart murmur, clubbing of fingers and toes, and other symptoms. Laboratory examinations may show leukocytosis, anemia, rapid erythrocyte sedimentation rate, positive blood culture, as well as vegetations and other powerful identifiers in echocardiography. ${ }^{[5]}$ In recent years, however, many atypical IE patients had complications as their initial symptoms. For example, some studies showed that about one-third of IE patients developed stroke. ${ }^{[6]}$

Our patient also got atypical IE features: considering his symptoms, it is quite natural to associate fever with headache, vomiting and epileptic seizures. He seemed to respond well to the initial treatment of intravenous acyclovir and mannitol. For this reason, he was diagnosed as encephalitis. However, negative results of CSF test were not in favour of this conclusion. After reconsidering the whole course of disease, it was hypothesized that all his symptoms were part of a basilar syndrome. In fact, except heart murmur or nervous system manifestations, there was no other sign. The echocardiography of the patient ultimately confirmed there was a vegetation $(10 \mathrm{~mm}$ $\times 4 \mathrm{~mm}$ ) attached to mitral valves. This is a strong predictive factor of embolic events. ${ }^{[7]}$ Besides, from the MRI results, we noticed there were lesions in bilateral cerebellar hemisphere of his brain. This was not among the commonest locations for herpes simplex encephalitis (in fact, characteristic changes are in the temporal lobes) and there was some evidence to support cardioembolism. Thus, it is likely that an event of cardiac embolism has taken place, since many areas of intracranial arteries were affected, especially bilateral lesions (or lesions in both anterior and posterior circulation). ${ }^{[8]}$ For our patient, his DWI results were in agreement with our diagnosis, in fact all the lesions were distributed in multiple areas in posterior circulation. This is consistent with cardioembolic lesions in IE patients. ${ }^{[9]}$ Additionally, continual variant symptoms occurred as expected in cardioembolism.

Based on the patient's clinical manifestations, it was very likely that streptococci caused his infective endocarditis. For this reason, penicillin was chosen as first line treatment. However, blood culture and anti-streptolysin $O$ test were both negative. It is worth noting here that there might be several explanations 
to support our results. Firstly, negative blood-culture occurs in $2.5-31 \%$ of all cases of IE, so the negative results are not totally unexpected. ${ }^{[1]}$ Secondly, antistreptolysin $O$ test is a test for activity of Lancefield's Group A streptococci (or occasionally Groups C and G). The intensity of the response varies with the duration of activity of the stimulus. The maximum response does not generally develop before 5 or 6 weeks, and it may be partially suppressed by antibiotic therapy. ${ }^{[10]}$ In this case, after the initial symptom characterized by fever, infusion was given to lower patient temperature. However, the patient does not recollect which infusion was administered. While antibiotics abuse is a common phenomenon in China, we hypothesize that such infusion may be some sort of antibiotic therapy. The patient was hospitalized in our clinic within 2 weeks after the fever, and it is also possible that the response may not develop to a maximum level. All the factors listed here may have led to negative blood tests, but the effect of penicillin cannot be excluded. Regarding the use of anti-platelet agents, it is suggested that this treatment can be prolonged in absence of bleeding. ${ }^{[1]}$ Aspirin is classical anti-platelet agent but may cause Reye syndrome in children. ${ }^{[12,13]}$ Considering that the patient was only 12 years old it was agreed to treat him with clopidogrel 1 $\mathrm{mg} / \mathrm{kg}$ daily, instead of aspirin. Of note, there was no sign of recurrence after six months of follow-up.

In conclusion, here we report a patient with embolic stroke as a consequence of endocarditis. Atypical IE manifestation is likely to cause misdiagnosis and clinicians should be cautious when considering its symptoms. We hope that the case presented here will also help clinicians to diagnose IE and its complications, as well as carry out early treatments to reduce morbidity and mortality.

\section{Financial support and sponsorship}

Nil.

\section{Conflicts of interest}

There are no conflicts of interest.

\section{REFERENCES}

1. Habib G, Hoen B, Tornos P, Thuny F, Prendergast B, Vilacosta I, Moreillon P, de jesus Antunes M, Thilen U, Lekakis J, Lengyel M, Muller L, Naber CK, Nihoyannopoulos P, Moritz A, Zamorano JL; ESC Committee for Practice Guidelines. Guidelines on the prevention, diagnosis, and treatment of infective endocarditis (new version 2009): the task force on the prevention, diagnosis, and treatment of infective endocarditis of the European Society of Cardiology (ESC). Endorsed by the European Society of Clinical Microbiology and Infectious Diseases (ESCMID) and the International Society of Chemotherapy (ISC) for Infection and Cancer. Eur Heart J 2009;30:2369-413.

2. Habib G. Embolic risk in subacute bacterial endocarditis: determinants and role of transesophageal echocardiography. Curr Infect Dis Rep 2005;7:264-271.

3. Fugate JE, Lyons JL, Thakur KT, Smith BR, Hedley-Whyte ET, Mateen FJ. Infectious causes of stroke. Lancet Infect Dis 2014;14:869-80.

4. Thuny F, Di Salvo G, Belliard O, Avierinos JF, Pergola V, Rosenberg V, Casalta JP, Gouvernet J, Derumeaux G, Iarussi D, Ambrosi P, Calabró R, Riberi A, Collart F, Metras D, Lepidi H, Raoult D, Harle JR, Weiller PJ, Cohen A, Habib G. Risk of embolism and death in infective endocarditis: prognostic value of echocardiography: a prospective multicenter study. Circulation 2005;112:69-75.

5. Bayer AS, Bolger AF, Taubert KA, Wilson W, Steckelberg J, Karchmer AW, Levison M, Chambers HF, Dajani AS, Gewitz MH, Newburger JW, Gerber MA, Shulman ST, Pallasch TJ, Gage TW, Ferrieri P. Diagnosis and management of infective endocarditis and its complications. Circulation 1998;98:2936-48.

6. Ma Y, Zhang H, Liu YY, Pan SN, Meng QP. Clinical and image characteristics of cerebrovascular complications of infective endocarditis. Chin J Mod Med 2008;18:760-3, 767

7. Iung B, Tubiana S, Klein I, Messika-Zeitoun D, Brochet E, Lepage L, Al-Attar N, Ruimy R, Leport C, Wolff M, Duval X; ECHO-IMAGE Study Group. Determinants of cerebral lesions in endocarditis on systematic cerebral magnetic resonance imaging: a prospective study. Stroke 2013;44:3056-62.

8. Bogousslavsky J, Cachin C, Regli F, Despland PA, Van Melle G, Kappenberger L. Cardiac sources of embolism and cerebral infarction-clinical consequences and vascular concomitants: the Lausanne Stroke Registry. Neurology 1991;41:855-9.

9. Ruttmann E, Willeit J, Ulmer H, Chevtchik O, Höfer D, Poewe W, Laufer G, Müller LC. Neurological outcome of septic cardioembolic stroke after infective endocarditis. Stroke 2006;37:2094-9.

10. Lawy HS. Use and interpretation of the antistreptolysin test. Ann Rheum Dis 1960;19:42-7.

11. Hoen B, Duval X. Clinical practice. Infective endocarditis. N Engl J Med 2013;368:1425-33.

12. Li JS, Yow E, Berezny KY, Bokesch PM, Takahashi M, Graham TP Jr, Sanders SP, Sidi D, Bonnet D, Ewert P, Jennings LK, Michelson $\mathrm{AD}$; PICOLO Investigators. Dosing of clopidogrel for platelet inhibition in infants and young children: primary results of the Platelet Inhibition in Children On cLOpidogrel (PICOLO) Trial. Circulation 2008;117:553-9.

13. Lacroix D, Sonnier M, Moncion A, Cheron G, Cresteil T. Expression of CYP3A in the human liver--evidence that the shift between CYP3A7 and CYP3A4 occurs immediately after birth. Eur J Biochem 1997;247:625-34. 